\title{
IMPACTO DA TEMPERATURA, IRRAdîANCIA E PROFUndIDAde DAS Sementes NA EMERgÊnCIA E GeRminaÇÃo de Conyza bonariensis E Conyza canadensis RESISTENTES AO GlYPHOSATE ${ }^{1}$
}

\author{
Impact of Temperature, Light and Seed Depth on Emergence and Germination of Conyza \\ bonariensis e Conyza canadensis Resistant to Glyphosate
}

VIDAL, R.A. ${ }^{2}$, KALSING, A. ${ }^{3}$, GOULART, I.C.G.R. ${ }^{3}$, LAMEGO, F.P. ${ }^{4}$ e CHRISTOFFOLETI, P.J. ${ }^{5}$

\begin{abstract}
RESUMO - O uso intenso de glyphosate em sistemas de produção de frutíferas e soja - em especial no sistema de semeadura direta da soja - favoreceu a seleção de biótipos resistentes ao glyphosate em Conyza bonariensis e C. canadensis (buva). Estudos da biologia destas espécies subsidiariam a proposição de estratégias visando o seu manejo integrado. Um programa de pesquisa foi desenvolvido com o objetivo de avaliar como a germinação das duas espécies foi influenciada pelas populações, composição do substrato de semeadura, profundidade da semente no perfil do substrato, temperatura e luz. Num primeiro experimento, os tratamentos foram organizados em esquema fatorial, em que o fator A consistiu das populações (duas de cada espécie), o fator B foi atribuído à composição do substrato (terra, areia e terra:areia) e o fator $\mathrm{C}$ foram as profundidades no perfil do substrato $(0,0,5,1,2$ e $5 \mathrm{~cm})$. No segundo experimento, foram testados o fator A; o fator B, que foi a temperatura (constante de 20,25 ou $30^{\circ} \mathrm{C}$, e alternada: $20 / 30{ }^{\circ} \mathrm{C}$ ); e o fator $\mathrm{C}$, a condição luminosa (luz, escuro). No terceiro experimento, os fatores consistiram de espécies e temperatura $\left(10,15,20,25\right.$ e $\left.30^{\circ} \mathrm{C}\right)$. Avaliaram-se a emergência de plântulas ou a germinação de sementes aos 12 dias após a instalação do experimento. De acordo com os resultados, chegou-se às seguintes conclusões: todos os biótipos das duas espécies tiveram emergência semelhante em relação ao perfil do solo; o aumento da profundidade da semente no perfil do solo reduziu a emergência de plântulas; o substrato arenoso favoreceu a germinação de sementes posicionadas a 0,5 e a $1,0 \mathrm{~cm}$ de profundidade; as duas espécies são fotoblásticas positivas; a temperatura ótima para germinação das espécies foi de $20{ }^{\circ} \mathrm{C}$, mas $C$. canadensis apresentou germinação melhor em temperaturas inferiores à ótima e $C$. bonariensis germinou melhor em temperaturas superiores a esta.
\end{abstract}

Palavras-chave: emergência, germinação, luz, temperatura, profundidade do solo.

ABSTRACT - Intense glyphosate use either in orchards or specially no-tilled glyphosate-resistant soybeans, has selected resistant biotypes of both Conyza bonariensis and C. canadensis. Studies of the species biology could provide insight for integrated weed management. A research program was designed to evaluate how seed germination of both species was affected by the following factors: biotype, substrate composition, soil depth, temperature and light. A factorial arrangement of the treatments was established for the first experiment, where factor $A$ consisted of biotypes (two from each species); factor B was substrate composition (soil, sand, soil: sand); and factor $C$ was substrate depths $(0,0.5,1,2,5 \mathrm{~cm})$. The second experiment included the first factor; plus factor $B$ as temperature (constant 20,25 , or $30^{\circ} \mathrm{C}$, and alternating $20 / 30^{\circ} \mathrm{C}$ ), and factor $C$ as light conditions (light, dark). In a third experiment, factors consisted of species and temperature $\left(10,15,20,25,30^{\circ} \mathrm{C}\right)$. Seedling emergence or seed germination were assessed at

Recebido para publicação em 17.1.2007 e na forma revisada em 15.5.2007.

Eng ${ }^{\circ}$-Agr ${ }^{\circ}$, Ph.D., Prof. da Faculdade de Agronomia da Universidade Federal do Rio Grande do Sul - UFRGS, Caixa Postal 15.100, 90001-970, Porto Alegre-RS, Bolsista do CNPq, <ribas.vidal@ufrgs.br>; ${ }^{3}$ Estudante da Faculdade de Agronomia da UFRGS, bolsista de Iniciação Científica do CNPq; ${ }^{4} \mathrm{Eng}^{\mathrm{a}}-\mathrm{Agr}^{\mathrm{o}}$, M.S., aluna de doutorado do Programa de Pós-Graduação em Fitotecnia da UFRGS. Bolsista do CNPq; ${ }^{5}$ Eng - -Agro - Ph.D., Prof. da Escola Superior de Agricultura "Luiz de Queiroz". Bolsista do CNPq. 
12 days after treatments. All biotypes from both species had similar seedling emergence in relation to soil depth. Increasing soil depth reduced seedling emergence. Sandy substrate facilitated seed germination at 0.5 and $1.0 \mathrm{~cm}$ depth. The species are positive photoblastic. Optimum temperature for seed germination for both species was $20^{\circ} \mathrm{C}$, but C. canadensis germinates betterattemperatures below the optimum and $\mathbf{C}$. bonariensis germinates better at temperatures above the optimum.

Keywords: emergence, germination, light, temperature, soil depth.

\section{INTRODUÇÃO}

Conyza bonariensis (L.) (ERIBO, buva) e Conyza canadensis (L.) (ERICA, buva) são espécies da família Asteraceae, com centro de dispersão nas Américas do Sul e Norte, respectivamente. ERIBO ocorre intensamente nas zonas subtropicais e temperadas da América do Sul (Kissmann \& Groth, 1999), enquanto ERICA é uma das espécies mais distribuídas do mundo, principalmente nas regiões de clima temperado ou subtropical do hemisfério norte e nas regiões subtropicais do hemisfério sul (Holm et al., 1997). Na cultura da soja sob plantio direto, 150 plantas por $\mathrm{m}^{2}$ de ERICA reduziram em $83 \%$ o rendimento de grãos (Bruce $\&$ Kells, 1990).

O hipocótilo e epicótilo são imperceptíveis, de modo que as plântulas formam no solo uma roseta para posteriormente desenvolverem o caule. As plantas são herbáceas, eretas e a estatura depende das condições em que se desenvolvem, podendo chegar a $2 \mathrm{~m}$ de altura. ERICA diferencia-se por apresentar a margem das folhas denteadas e ramos laterais que não ultrapassam a inflorescência, enquanto ERIBO apresenta margens foliares não-serrilhadas (Lorenzi, 2000). A produção média por planta é de 110 mil aquênios (sementes) para ERIBO (Wu \& Walker, 2004) e de 200 mil para ERICA (Bhowmik \& Bekech, 1993), e $80 \%$ das sementes germinam próximo à planta-mãe (Loux et al., 2006).

O efeito da profundidade em que se encontra a semente na emergência de ERICA tem sido contraditório na literatura. Um trabalho realizado em solo argilo-arenoso (Nandula et al., 2006) relata elevada emergência de plântulas de ERICA quando as sementes estavam posicionadas na superfície do solo, mas com emergência de plântulas drasticamente reduzida já na profundidade de $0,25 \mathrm{~cm}$. Em contraste, outro trabalho realizado em solo mais arenoso (Bhowmik \& Bekech, 1993) mostrou elevada emergência mesmo quando as sementes se encontravam a $2 \mathrm{~cm}$ de profundidade.

No Brasil, o controle dessas espécies é realizado com herbicidas, e o inibidor da enzima en ol-pir uvil-s hi ki ma to -f os fa to - $s$ in te ta se (EPSPS) é principalmente utilizado nas áreas cultivadas com soja resistente ao glyphosate e/ou com frutíferas perenes. Contudo, foram identificados biótipos resistentes ao glyphosate em pomares de citros (Christoffoleti et al., 2006; Montezuma et al., 2006; Moreira et al., 2006); o mesmo ocorre com ERIBO em áreas de soja transgênica (Vargas et al., 2006; Lamego \& Vidal, 2007). A ocorrência de biótipos resistentes aos herbicidas indica a necessidade de técnicas de manejo integrado de plantas daninhas. Para realizar o manejo integrado de ERIBO e ERICA, é necessário conhecer ou obter maiores informações sobre a germinação das sementes e a emergência das plântulas dessas espécies. As condições ambientais como luminosidade, temperatura e a interação entre ambas e destas com os atributos do solo são os principais fatores ambientais que regulam a germinação e a emergência de plântulas (Frankland \& Taylorson, 1983; Baskin \& Baskin, 1998). Trabalhos realizados com ERICA (Nandula et al., 2006) indicam que a temperatura ótima para germinação das sementes situa-se entre 20 e $25{ }^{\circ} \mathrm{C}$ e que a presença de luz favorece a germinação das sementes.

Este trabalho teve por objetivo avaliar o efeito de espécie, temperatura, irradiância, posição das sementes no perfil e tipo de substrato 
sobre a germinação e emergência de ERIBO e ERICA resistentes ao glyphosate.

\section{MATERIAL E MÉTODOS}

\section{Origem das sementes}

Capitulos contendo sementes em fase final de maturação de ERIBO foram coletados no municipio de Matão, SP, em área cultivada com citros há vários anos. Também foram coletadas sementes no municipio de Victor Graeff, RS, onde há produção de soja. Já para ERICA, a coleta foi realizada nos municipios de Cruz Alta e Victor Graeff, RS, ambos com produção de soja. Todas as lavouras onde foram coletadas as sementes apresentavam histórico de aplicação de glyphosate durante vários anos. Após a coleta, os capítulos foram secos à temperatura ambiente $\left(18\right.$ a $\left.22{ }^{\circ} \mathrm{C}\right)$, sendo então extraídos os aquênios (sementes). As sementes sem deformações foram selecionadas. Testes preliminares confirmaram a resistência ao glyphosate de todas as populações utilizadas.

\section{Experimentos}

A fim de atender aos objetivos do trabalho, foram realizados três experimentos. Para avaliar o efeito de populações, substrato e profundidade da semente foi realizado um experimento em esquema fatorial (4 x 5 x 3), com repetições. O delineamento experimental utilizado foi o inteiramente casualizado. O fator A foi atribuído às populações (duas populações de ERIBO e duas de ERICA, conforme descrito anteriormente); o fator $\mathrm{B}$, à profundidade da semente no substrato $(0 ; 0,5 ; 1,0 ; 2,0 ;$ e $5,0 \mathrm{~cm}$ ); e o fator $\mathrm{C}$, ao substrato (terra, areia, terra:areia $(50: 50 \mathrm{v}: \mathrm{v}))$. A terra utilizada era argilosa, com coloração marrom-escura e com teores de argila e areia descritos na Tabela 1 .

Para realização do experimento, cinco sementes foram colocadas em recipientes com capacidade para $300 \mathrm{~mL}$ e $8 \mathrm{~cm}$ de profundidade, contendo os substratos descritos. A irrigação foi mantida por subirrigação. Todos os vasos foram mantidos em casa de vegetação pertencente à Universidade Federal do Rio Grande do Sul, em Porto Alegre-RS, sob temperaturas diurnas / noturnas médias de $27 / 20^{\circ} \mathrm{C}$ e fotoperiodo de 12 horas (setembro-outubro). O critério utilizado na identificação da emergência das plântulas foi a visualização do hipocótilo na superficie do substrato.

Um segundo experimento foi realizado para avaliar o efeito de populações, temperatura e luz, tendo sido conduzido em esquema fatorial $(4 \times 4 \times 2)$ com repetições. O delineamento experimental foi o inteiramente casualizado. $\mathrm{O}$ fator A foi atribuído às populações (duas populações de ERIBO e duas de ERICA, conforme já descrito); o fator $\mathrm{B}$, à temperatura $(20,25,30$ e $20 / 30^{\circ} \mathrm{C}$, sendo esta última condição caracterizada por 12 horas a $20{ }^{\circ} \mathrm{C}$ e 12 a $30{ }^{\circ} \mathrm{C}$ a cada ciclo de 24 horas); e o fator $\mathrm{C}$, à irradiância (presença-ausência).

Dez sementes foram posicionadas equidistantes em placas de Petri de $9 \mathrm{~cm}$ de diâmetro, sobre papel para germinação. Foram adicionados às placas $10 \mathrm{~mL}$ de água destilada, as quais foram acondicionadas em câmaras de crescimento com controle automático de temperatura, conforme a necessidade do tratamento. A condição ausência de irradiância foi obtida com a manipulação dos materiais no interior de uma câmara escura e posterior envolvimento das placas de Petri em lâmina de alumínio flexível. Para este tratamento (escuro), embalaram-se placas de Petri em quantidade suficiente para avaliações destrutivas em cada período de determinação. O critério utilizado na comprovação da germinação foi a visualização da radícula, com extensão de $2 \mathrm{~mm}$.

Para avaliar o efeito de espécies e temperatura, foi conduzido um experimento em esquema fatorial $(2 \times 5)$ com repetições. O delineamento experimental utilizado foi o inteiramente casualizado. $O$ fator $A$ foi atribuído às espécies (ERIBO e ERICA, ambas do RS, conforme já descrito); e o fator $\mathrm{B}$, à temperatura (10, $15,20,25$ e $30^{\circ} \mathrm{C}$ ). Detalhes experimentais, como número de sementes e acondicionamento nas placas de Petri, e o critério para germinação foram já descritos no experimento anterior.

\section{Avaliações e análises}

Em todos os experimentos foi avaliado o percentual de sementes germinadas/emergidas aos 12 dias após o início do experimento (DAI). Os dados foram submetidos à análise 
Tabela 1 - Textura e teores (\%) de argila, silte e areia dos substratos utilizados no primeiro experimento

\begin{tabular}{|l|l|c|c|c|}
\hline \multicolumn{1}{|c|}{ Substrato } & \multicolumn{1}{|c|}{ Textura } & Argila & Silte & Areia \\
\hline Terra & Franca & 19 & 27 & 54 \\
\hline Terra: areia & Franco-arenosa & 9 & 19 & 72 \\
\hline Areia & Arenosa & 2 & 9 & 89 \\
\hline
\end{tabular}

de variância, e a comparação das médias ocorreu com teste $\mathrm{t}$ a $5 \%$ de probabilidade.

\section{RESULTADOSE DISCUSSÃO}

A análise de variância da interação entre populações, substrato e profundidade da semente no substrato revelou que o padrão de emergência de plântulas de buva não diferiu entre as quatro populações avaliadas; são apresentados na Figura 1 os resultados médios da interação substrato $x$ profundidade $(P<0,05)$. Houve correlação negativa entre a profundidade da semente nos diferentes tipos de substrato estudados e a emergência das plântulas. Quando as sementes foram posicionadas na superficie dos substratos, a emergência de plântulas (germinação) atingiu valor de $80 \%$, em média, para os três substratos testados; a $5,0 \mathrm{~cm}$ de profundidade, ela foi inferior a 4\%, em todos os substratos. As diferenças de germinação entre os substratos dentro em uma mesma profundidade foram mais evidentes nas profundidades de 0,5 a $1,0 \mathrm{~cm}$, atingindo diferenças de $40 \%$ de germinação para o substrato areia, ao passo que a menor emergência foi de $10 \%$ de germinação para o substrato terra, na profundidade de 1,0 cm (Figura 1).

Os resultados da interação entre os substratos e a profundidade da semente (Figura 1) explicam, em parte, as informações contraditórias apresentadas na introdução sobre a emergência de ERICA, relatadas por Bhowmik \& Bekech (1993) e Nandula et al. (2006). Assim, em solos de textura leve (arenosos) há boa germinação da buva até $1,0 \mathrm{~cm}$ de profundidade (Bhowmik \& Bekech, 1993), porém naqueles de textura pesada (argilosos) o enterrio das sementes de buva, mesmo que em pequenas profundidades, reduz significativamente a emergência (Nandula et al., 2006).

O efeito da redução da germinação com o aumento da profundidade de colocação das

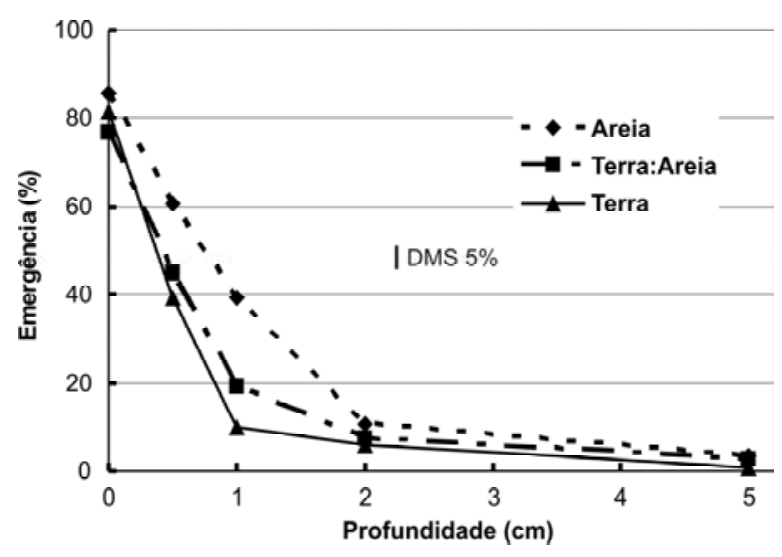

Figura 1 - Emergência de buva nos três substratos e nas cinco profundidades das sementes no substrato, avaliada aos 12 dias após a semeadura. Cada ponto no gráfico representa a média de 24 repetições. Barra vertical indica diferença mínima significativa (DMS) $(\mathrm{P}<0,05)$ para comparar resultado entre dois substratos em cada profundidade.

sementes (Figura 1) provavelmente deve estar associado à reduzida capacidade de reservas de energia das sementes de buva, em razão de seu peso diminuto (Kissmann \& Groth, 1999). O resultado da interação negativa entre profundidade da semente de buva e emergência também pode explicar a alta incidência e adaptabilidade dessa planta daninha aos sistemas conservacionistas (plantio direto), em que o revolvimento do solo é praticamente nulo, sendo as sementes dispersas dessa planta daninha posicionadas na superficie do solo, facilitando assim a emergência e adaptabilidade ao sistema. Da mesma forma, a linha de culturas perenes, em especial a do citros, em que o manejo de plantas daninhas é feito com herbicidas pós-emergentes, sem o revolvimento do solo, também favorece o posicionamento da semente de buva na superficie do solo e, dessa forma, sua alta adaptabilidade à cultura.

A análise de variância dos resultados da interação entre populações, temperatura e luz revelou que não ocorreu efeito dos fatores referentes à população, devendo, portanto, ser analisados os dados da interação entre regimes de temperatura e luz de forma conjunta (Figura 2). Em cada regime de temperatura, a germinação de sementes foi menor na condição de escuro que na presença de luz. A máxima germinação obtida foi de $78 \%$, quando as sementes estavam submetidas à temperatura constante 


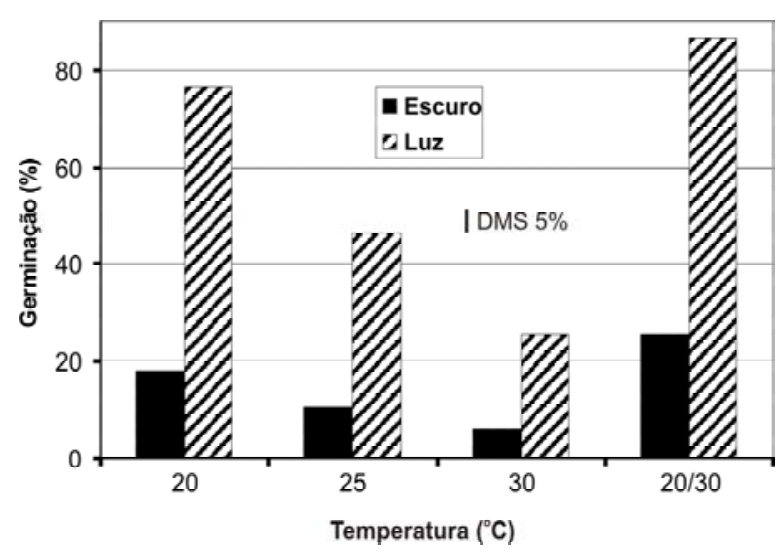

Figura 2 - Germinação de buva em quatro regimes térmicos e dois níveis luminosos, avaliada aos 12 dias após a semeadura. Cada ponto no gráfico representa a média de 16 repetições. Barra vertical indica diferença mínima significativa (DMS) $(\mathrm{P}<0,05)$ para comparar resultado entre os regimes térmicos e de luminosidade.

de $20{ }^{\circ} \mathrm{C}$ e na presença de luz. Com a elevação da temperatura constante para $30{ }^{\circ} \mathrm{C}$, houve redução da germinação de buva, constatandose germinação de $22 \%$ na presença de luz e de apenas $4 \%$ na ausência de luz. A alternância entre as temperaturas de 20 e $30^{\circ} \mathrm{C}$ levou a resultados semelhantes, estatisticamente, aos da temperatura constante de $20{ }^{\circ} \mathrm{C}$ (Figura 2).

Sabe-se que a maioria das espécies de plantas daninhas (espécies fotoblásticas positivas) requer a incidência de certa quantidade de luz para iniciar o processo de germinação (Radosevich et al., 1997); essa luz e o requerimento de temperatura funcionam como sensores de posicionamento da semente no solo e de condições de sombreamento, em relação aos vegetais adultos vizinhos. As sementes das espécies fotoblásticas positivas localizadas em profundidade não recebem luz e, portanto, não teriam capacidade de responder às alterações da temperatura que ocorrem durante o ano ou às flutuações de temperatura do decorrer do dia. Da mesma forma, sementes posicionadas na superficie do solo - mas na presença de vegetação adulta vizinha ou sob densos resíduos vegetais (palha) - também não responderiam à temperatura, por estarem em ambiente escuro (Guersa et al., 1992). Os resultados experimentais obtidos na presente experimentação evidenciam que a buva é uma planta daninha fotoblástica positiva e que sua emergência em solos com sistemas de produção de baixo distúrbio (plantio direto e áreas de fruticultura) é justificada por essa característica. Também, os resultados justificam a presença da planta daninha em períodos de temperaturas mais amenas durante o ano, ou seja, na época de dessecação para plantio das culturas de inverno e na cultura do citros durante a primavera, o que é evidenciado pela maior germinação da buva na temperatura de $20{ }^{\circ} \mathrm{C}$ (Figura 2).

Os resultados da Figura 3 evidenciam que a elevação da temperatura de 10 para $30{ }^{\circ} \mathrm{C}$ promove incremento na germinação até um pico e, subseqüentemente, redução da germinação em temperaturas maiores. A temperatura ótima para germinação de ERIBO e ERICA é $20^{\circ} \mathrm{C}$; contudo, esta última apresentou melhores níveis de germinação em temperaturas menores que $20^{\circ} \mathrm{C}$, e a primeira, em temperaturas maiores que $20^{\circ} \mathrm{C}$ (Figura 3). Essa característica provavelmente é uma estratégia de escalonamento da ocupação do terreno com as mudanças de temperatura que ocorrem no decorrer das estações do ano. Dessa forma, ocupará o nicho aquela espécie cujos requerimentos de temperatura estejam apropriados, num momento em que as condições do ambiente estejam adequadas e o terreno esteja desocupado de vegetação (indicador luz) (Radosevich et al., 1997).

Pelos resultados obtidos neste trabalho, é possivel inferir algumas técnicas para o manejo integrado de ERIBO e ERICA. A germinação de sementes de buva desfavorecida pela ausência de luz sugere que práticas mecânicas ou culturais que minimizem a exposição das sementes à luz e aumentem sua profundidade no perfil do solo reduziriam sua germinação. Como exemplo de métodos mecânicos destaca-se o preparo do solo com arações ou gradagens. Em se tratando de métodos culturais, salienta-se a presença maciça de cobertura do solo $\left(>7 \mathrm{t} \mathrm{ha}^{-1}\right)$ com resíduos vegetais (palha). Esses métodos representam estratégias biologicamente suportadas para o manejo da espécie, em parte, devido ao menor acesso das sementes à luz e à menor resposta às flutuações térmicas (Frankland \& Taylorson, 1983; Baskin \& Baskin, 1998).

Este trabalho demonstrou que sementes de Conyza bonariensis e C. canadensis têm germinação influenciada de forma semelhante 


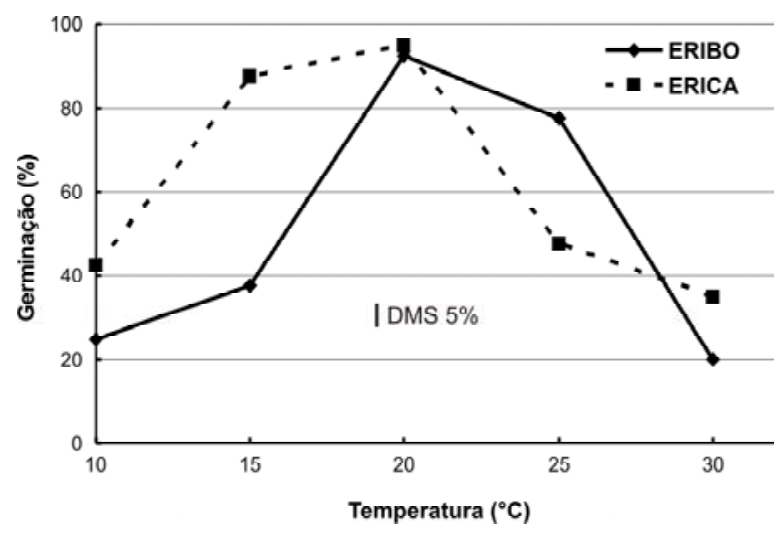

Figura 3 - Germinação de sementes de Conyza bonariensis (ERIBO) e C. canadens is (ERICA), em cinco regimes térmicos, avaliada aos 12 dias após a semeadura. Média de quatro repetições. Barra vertical indica diferença mínima significativa (DMS) $(\mathrm{P}<0,05)$ para comparar resultado entre as duas espécies de buva em cada temperatura.

quanto à profundidade de posicionamento no perfil do solo, ao tipo de substrato e à presença de luz. Com o incremento da profundidade da semente no perfil do solo, há redução drástica da germinação. Substratos arenosos favorecem a germinação de sementes posicionadas aos 0,5 e $1,0 \mathrm{~cm}$. Sementes, de ambas as espécies, submetidas à condição luminosa têm germinação mais acentudada, independentemente do regime térmico. A temperatura ótima para germinação de ambas as espécies é de $20^{\circ} \mathrm{C}$, mas ERICA germina melhor em temperaturas inferiores à ótima, e ERIBO, em temperaturas superiores a esta.

\section{AGRADECIMENTOS}

Ao CNPq, CAPES, FAPESP e FAPERGS, pelo apoio ao projeto e aos pesquisadores.

\section{LITERATURA CITADA}

BASKIN, C. C.; BASKIN, J. M. Seeds: ecology, biogeography and evolution of dormancy and germination. San Diego: Academic Press, 1998. p. 81-86.

BHOWMIK, P. C.; BEKECH, N. N. Horseweed (Conyza canadensis) seed production, emergence, and distribution in no-tillage and conventional-tillage corn and conventional tillage com (Zea mays), Agron. Trends Agric. Sci., v. 1, p. 67-71, 1993.
BRUCE, J.; KELLS, J. Horseweed (Conyza canadensis) control. in no-tillage soybeans ( Glycine max) with preplant and preemergence herbicides. Weed Technol., v. 4, n. 3, p. $642-647,1990$.

CHRISTOFFOLETI, P. J. et al. Herbicidas alternativos para o controle de biótipos de buva ( $C$. bonariensis $e$ C. canadensis) supostamente resistentes ao herbicida glyphosate. In: CONGRESSO BRASILEIRO DE CIÊNCIA DAS PLANTAS DANINHAS, 25., Brasília, 2006. Resumos... Londrina: SBCPD, 2006. p. 553.

GHERSA, C. M.; BENECH, R. L.; MARTINEZ-GHERSA, $\mathrm{M}$. A. The role of fluctuating temperatures in germination and establishment of Sorghum hapelense. Regulation of germination at increasing depths. Funct. Ecol.,v. 66, p. 460468, 1992.

FRANKLAND, B.; TAYLORSON, R. Light control of seed germination. In: SHROPSHINE, W.; MOHR, H. (Eds). Photo morphogenesis. Berlin: Springer-Verlag, 1983, p. 428-456.

HOLM, E. et al. World weeds: Natural histories and distribution. Toronto: John Wiley \& Sons, 1997. p. 226-235.

KISSMANN, K. G.; GROTH, D. Plantas infestantes e nocivas. 2. ed. São Paulo: BASF, 1999. v. 2. 978 p.

LAMEGO, F. P.; VIDAL, R.A. Resistência ao glyphosate em biótipos de Conyza bonariensis e Conyza canadensis no estado do Rio Grande do Sul, Brasil. Planta Daninha, v. 25, 2007. (no prelo)

LORENZI, H. Plantas daninhas do Brasil: terrestres, aquáticas, parasitas, tóxicas e medicinais. 3. ed. Nova Odessa: Instituto Plantarum, 2006. 339 p.

LOUX, M. et al. Biology and management of horseweed. Disponível em: $<$ http://www.ipm.uiuc.edu/pubs/ horseweed.pdf $>$.

MONTEZUMA, M. C. et al. Avaliação da suspeita de buva (C. bonariensis e C. canadensis) ao herbicida glyphosate em pomares de citros no estado de São Paulo. In: CONGRESSO BRASILEIRO DE CIÊNCIA DAS PLANTAS DANINHAS, 25., Brasília, 2006. Resumos... Londrina: Sociedade Brasileira da Ciência das Plantas Daninhas, 2006. p. 564.

MOREIRA, M. S. et al. Resistência de buva (Conyza bonariensis ) ao herbicida glyphosate em pomares de citros no estado de São Paulo. In: CONGRESSO BRASILEIRO DE CIÊNCIA DAS PLANTAS DANINHAS, 25., Brasília, 2006. Resumos... Londrina: Sociedade Brasileira da Ciência das Plantas Daninhas, p. 554-555.

NANDULA, V. K. et al., Factors affecting germination of horseweed (Conyza canadensis). Weed Sci., v. 54, n. 5, p. 898-902, 2006.

RADOSEVICH, S.; HOLT, J.; GHERSA, C. Weed ecology: implications for management. 2. ed. New York: John Wiley \& Sons, 1997. p. 103-161. 
VARGAS, L. et al. Resistência de Conyza bonariensis ao herbicida glyphosate. In: CONGRESSO BRASILEIRO DE CIÊNCIA DAS PLANTAS DANINHAS, 25., Brasília, 2006. Resumos...Londrina: Sociedade Brasileira da Ciência das Plantas Daninhas, 2006. p. 540.
WU, H.; WALKER, S. Fleabane: Fleabane biology and control. Disponível em: $<$ http://www.weeds.crc.org.au/ documents/fleabane.pdf $>$. 